\title{
VISUAL REACTION TIME: HOW IT RELATES TO BODY MASS INDEX, DOMINANT AND NON-DOMINANT HAND IN HEALTHY YOUNG FEMALES
}

\author{
Reena Kumari Jha, ${ }^{1}$ Samjhana Thapa, ${ }^{2}$ Roshan Kasti, ${ }^{3}$ Sumi Singh ${ }^{4}$
}

${ }^{1}$ Department of Physiology, KUSMS, ${ }^{2}$ Bachelor of Science in Human Biology, ${ }^{3}$ Research and Development Division, Dhulikhel Hospital, Kavre, Nepal, ${ }^{4}$ Department of Emergency, Dirghayu Guru Hospital and Research Center, Budhang Marg, Kathmandu, Nepal

\section{ABSTRACT}

Reaction time is an indirect index of the processing speed of the central nervous system. It is affected by several factors including dominant and non-dominant hands and obesity. Obesity can be measured by body mass index. Thus, the aim of this study was to find out the relationship between body mass index, dominant and non-dominant hand with visual reaction time in healthy young females. A cross-sectional study was conducted in the Department of Physiology, among 89 females. The height and weight were recorded, and the body mass index was calculated. The subjects were divided into four groups, underweight, normal weight, overweight, and obese according to WHO criteria. Visual reaction time was measured using the ruler drop method in milliseconds. The data were analyzed by using the paired t-test and one-way ANOVA using the IBM Statistical Package for the Social Sciences version 22. Out of 89 participants, $26(29.21 \%)$ were underweight, 47 (52.80\%) had normal weight, 12 (13.48\%) and four (4.49\%) were overweight and obese with mean reaction time in the dominant hand and non-dominant hand were $(176.75 \pm 16.68$ vs. $186.58 \pm 16.21),(175.12 \pm 15.03$ vs. $185.43 \pm 15.64)$, (188.74 \pm 16.07 vs. $190.70 \pm 17.88)$, and $(200.7 \pm 9.77$ vs. $210.50 \pm 9.50)$ respectively. All participants were right-handers. In right-handers, the right hand reacted faster than the left hand. Reaction time was prolonged in underweight, overweight,and obese; when compared with normal weight individuals. Our study showed that the reaction time of people appears to be influenced by body mass index, dominant, and non-dominant hand, which was an indirect measure of the sensory motor association.

\section{KEYWORDS}

Body mass index, dominant hand, nondominant hand, visual reaction time

Received on: July 5, 2021

Accepted for publication: November 04, 2021

\section{CORRESPONDING AUTHOR}

Dr. Reena Kumari Jha,

Assistant Professor,

Department of Physiology

KUSMS, Dhulikhel, Kavre, Nepal

Email: reena2017dec@gmail.com

Orcid No: https://orcid.org/0000-0002-3172-2116

DOI: https://doi.org/10.3126/nmcj.v23i4.42248 


\section{INTRODUCTION}

Visual reaction time (VRT) is the time taken by an individual between the application of visual stimulus and initiation of the response. ${ }^{1}$ It evaluates the central neuronal processing and thus determines sensory-motor integrity, performance, and cortical arousal. ${ }^{2}$ It can be affected by several factors such as age, gender, dominant and non-dominant hand, obesity, fatigue, distraction, alcohol, physical activity, personality type, stress, intelligence, etc. ${ }^{3}$ Prolonged reaction time denotes decreased performance. $^{4}$

Handedness is related to hemispheric specialization. ${ }^{5}$ Visual reaction time using dominant limb was studied. Reaction time(RT) was faster in the dominant hand when compared with the opposite hand ${ }^{6-8}$ Several studies have shown the influence of obesity or elevated body mass index (BMI) on cognitive functions, memory deficits, and executive dysfunction.9,10 Males with higher BMI had longer RT. ${ }^{11}$ In addition, another study found similar finding in healthy females..$^{12}$ However, no information related to this subject matter was found in Nepal. Thus, the purpose of this study was to find out the relation between body mass index (BMI), dominant and non-dominant hand with visual reaction time.

\section{MATERIALS AND METHODS}

The cross-sectional study was carried out in the Department of Physiology, Kathmandu University School of Medical Sciences, Chaukot; after the approval from the Institutional Review Committee of Kathmandu University School of Medical Sciences/Dhulikhel Hospital (IRC-KUSMS) from May 2020 to August 2020. Participants were informed about the test, its procedure, and its rationale. Eighty-nine female subjects who satisfied the inclusion and exclusion criteria were selected, and informed consents were obtained from them. The exclusion criteria applied were as follows: those taking any medications (psychotropic drugs - sedatives, hypnotics, tranquilizers; antihistamines; or antiepileptics) or hormonal preparations (that could alter the menstrual hormonal milieu), those having any physical illness or endocrinological disorders, irregular menstrual cycle, smokers, alcoholics, and athletes or - those involved in excessive physical activity were excluded from the study. The subjects were instructed to visit the department during the proliferative phase i.e., $8-10^{\text {th }}$ day of their menstrual cycle. Daily basal body temperature recordings formed the basis for this judgment.

Each subject was called individually to the departmental research lab, where they were asked to fill up the questionnaire. Hand preference was ascertained by eliciting questions for the hand she preferred for performing the activities such as eating meals, combing hair, brushing teeth, and writing. Based on the information obtained from the questionnaire, all the participants had a dominant right hand. While selecting the sample we didn't find left-handed people. The reaction time measurement was recorded for the dominant and non-dominant hands.

Height was measured without shoes, to the nearest $0.5 \mathrm{~cm}$ with the participant standing erect against the wall with heels together and touching the wall, and head held in an upright position. Weight was measured with minimum clothes and no footwear on a standardized weighing machine marked from 0 to $130 \mathrm{~kg}$ and was recorded to the nearest $0.5 \mathrm{~kg}$. Body mass index (BMI) was then calculated using the formula weight in kilograms divided by the square of the height in meters fweight (kg)/ height $\left(\mathrm{m}^{2}\right)$ \}. It was then summarized and categorized into underweight (less than $18.5 \mathrm{~kg} /$ $\mathrm{m}^{2}$ ), normal (18.5 to $24.9 \mathrm{~kg} / \mathrm{m}^{2}$ ), overweight $\left(25.0-29.9 \mathrm{~kg} / \mathrm{m}^{2}\right)$, and obese $\left(\mathrm{BMI}>30 \mathrm{~kg} / \mathrm{m}^{2}\right)$ in accordance with the WHO recommendation. ${ }^{13}$

Experimental protocol of visual reaction time by ruler drop method: The subject was made to sit on the chair placing one hand on the horizontal surface of the table near the edge. While applying the test, the thumb and index fingers were made open with distance of about $25 \mathrm{~mm}$ using the spacer. One edge of the ruler is placed in between the subject fingers vertically. Then the subject was instructed to catch the ruler as soon as possible once it was dropped. The distance at which the subject grabbed the ruler was noted. Before the test, each subject had a trial for two times after a demonstration. Then the procedure was repeated three times and the mean was taken. The reaction time was calculated as $\mathrm{t}=(\sqrt{ } 2 \mathrm{~d} / \mathrm{g})$ where $\mathrm{t}=$ reaction time, $\mathrm{d}=$ distance travelled by the ruler, $\mathrm{g}=9.81 \mathrm{~m} / \mathrm{s}^{2}$ (gravitational constant). ${ }^{14,15}$

Statistical Analysis: Data were entered into Microsoft Excel and analyzed using IBM Statistical Package for the Social Sciences version 22 software. The data were expressed as mean, standard deviations, and the data were analyzed using paired ' $t$ '-test and oneway ANOVA with post-hoc Tukey's HSD test. The p-value less than 0.05 was considered as significant. 


\section{RESULTS}

Table 1 shows the distribution of subjects according to anthropometric variables. There were 89 subjects which were distributed into four groups. In group I:- 26 (29.21\%) subjects, in group II:- $47(52.80 \%)$ subjects, in group III:12 (13.48\%) subjects, and in group IV:- 4(4.49\%) subjects were included. The one-way ANOVA was used for comparison between groups for continuous variables. The difference in mean age, weight, and body mass index of the subjects were significant among the four groups.

The reaction time was recorded in both right hand and left hand among the four groups and compared. The mean differences in the reaction time among the four groups were significant. Reaction time was prolonged in underweight, overweight, and obese when compared with normal weight participants.

All participants had a dominant right hand. The reaction time was recorded in both dominant as well as non-dominant hands among all four groups and compared. In right-handed individuals, visual reaction time was faster in the right hand than the left hand (Table 3).

\section{DISCUSSION}

The result of our study demonstrates that both underweight, as well as overweight, individuals had prolonged reaction time when compared with normal weight individuals. This finding is consistent with the observation of other workers. ${ }^{11,12,}{ }^{16-19}$ Overweight and obesity have been found to be associated with several medical conditions, like cardiovascular, pulmonary, and endocrine diseases, and influences cognitive function, attention, memory. ${ }^{9}$ Body mass index is used to classify overweight and obesity. ${ }^{13}$ Cerebral area that controls cognition, memory, vocabulary, speed processing, and reasoning is influenced by BMI. ${ }^{10}$ The exact mechanism of how obesity influences cognitive and speed processing is not clearly understood but there

\begin{tabular}{|lccccc|}
\hline \multicolumn{7}{|c|}{ Table 1: Anthropometric variables of the participants } \\
& Group I & Group II & Group III & Group IV & p value \\
\hline Frequency n (\%) & $26(29.21)$ & $47(52.80)$ & $12(13.48)$ & $4(4.49)$ & \\
Age (years) $($ Mean \pm SD) & $20.76 \pm 1.33$ & $19.80 \pm 1.37$ & $21.25 \pm 1.21$ & $21.25 \pm 1.50$ & 0.00 \\
Weight (Kg) (Mean \pm SD) & $43.92 \pm 4.03$ & $52.34 \pm 5.79$ & $67.5 \pm 6.38$ & $73.25 \pm 5.56$ & 0.00 \\
Height(meter) (Mean \pm SD) & $1.59 \pm 0.07$ & $1.57 \pm 0.06$ & $1.56 \pm 0.05$ & $1.52 \pm 0.05$ & 0.18 \\
BMI (Kg/m2) (Mean \pm SD) & $17.35 \pm 0.93$ & $20.99 \pm 1.81$ & $27.69 \pm 1.49$ & $31.45 \pm 0.58$ & 0.00 \\
\hline
\end{tabular}

Table 2: Comparison of Reaction time within BMI subgroups

\begin{tabular}{|llcccc|} 
& & RTRH(ms)* (Mean \pm SD) & p-value & RTLH(ms)** $($ Mean \pm SD) & p-value \\
\cline { 2 - 6 } BMI & Group I & $176.75 \pm 16.68$ & & $186.58 \pm 16.21$ & \\
& Group II & $175.12 \pm 15.03$ & & $185.42 \pm 15.64$ & \\
& Group III & $188.74 \pm 16.07$ & 0.002 & $190.70 \pm 17.88$ & 0.027 \\
& Group IV & $200.7 \pm 9.77$ & & $210.50 \pm 9.50$ & \\
\hline
\end{tabular}

${ }^{*} R T R H-$ Reaction time in right hand

${ }^{* *}$ RTLH- Reaction time in left hand

Table 3. Comparison of visual reaction time between right hand and Left hand

\begin{tabular}{|lccc|}
\hline & $\begin{array}{c}\text { Reaction time in dominant } \\
\text { hand ms (Mean } \pm \text { SD) }\end{array}$ & $\begin{array}{c}\text { Reaction time in non-dominant } \\
\text { hand ms (Mean } \pm \text { SD) }\end{array}$ & p-value \\
\hline Group I & $176.75 \pm 16.68$ & $186.58 \pm 16.21$ & 0.01 \\
Group II & $175.12 \pm 15.03$ & $185.42 \pm 15.64$ & 0.00 \\
Group III & $188.74 \pm 16.07$ & $190.70 \pm 17.88$ & 0.66 \\
Group IV & $200.70 \pm 9.77$ & $210.50 \pm 9.50$ & 0.00 \\
\hline
\end{tabular}


is a hypothesis suggesting that secretions of adipose tissue like hormones, cytokines, and growth factors affect brain health. ${ }^{20}$ Another possible mechanism could be a varying level of sex hormone in different phases of the menstrual cycle. Estrogen increases the level of plasma renin - which converts angiotensinogen into Angiotensin I. Angiotensin I is converted into Angiotensin II by the Angiotensinconverting enzyme (ACE), and this results in an elevated secretion of aldosterone. Aldosterone retains sodium and water. ${ }^{5}$ The retention of salt and water could modify the process of axonal conduction time and alter the availability of neurotransmitter at the synaptic level; changes in either of these two processes might affect the sensorimotor coordination and the processing speed of the central nervous system. ${ }^{21}$

In the present study, all the participants had the dominant right hand. In the right-handers, the dominant hand reacts faster when compared with the opposite hand. This observation concurs with those of the previous studies. ${ }^{6-}$ ${ }^{8,22}$ In contrast to our finding several authors found that reaction time was faster in the left hand compared to the right hand. ${ }^{23}$ Anuradha et. al. ${ }^{24}$ showed correlation exists between handedness and conduction velocity of the median nerve. In the right-handers, the right median nerve conducts faster, however in the left-hander, the left median nerve conducts faster than the right median nerve. Handedness is related to hemispheric specialization. A righthanded person is one who uses the right hand, preferentially performing activities like eating a meal, combing hairs, brushing teeth, and writing while the left handers prefer their left hand for the similar acts. In $96 \%$ of the righthanded persons, the left cerebral hemisphere is dominant or categorical however,in lefthanders, $15 \%$ have the right as dominant, $15 \%$ have no clear lateralization and, in the remaining $70 \%$ left hemisphere is the dominant one. Also, the right hemisphere controls the left hand, and the left hemisphere controls the right hand. ${ }^{5}$

Small sample size, number of participants unmatched among BMI subgroups, lack of lefthanded participants, lack of standard reference and reaction time measured by the ruler drop method are the limitations of this study. Further studies done in multiple institutes with - larger sample sizes and computer-based specialized software must be used to find out the real value of the reaction time.

In conclusion reaction time is influenced by both BMI and handedness. In right-handers, the right hand reacts faster than the left hand. Visual reaction time was prolonged in underweight as well as overweight, and obese groups; thus, maintenance of an optimal BMI, neither underweight nor overweight, is very much encouraged to everyone, especially among medical personals.

\section{ACKNOWLEDGEMENTS}

Our sincere thanks go to all the volunteers who participated in this study.

Conflict of interest: None

Source of research fund: None

\section{REFERENCES}

1. Pramanik T, Dahal R, Pandit R. Visual reaction time in people with and without diabetes - A comparative study. Nepal Med Coll J 2019; 21: 100-3.

2. Bhavanani AB, Ramanathan M, Balaji R, Puspa D. Differential effects of uninostril and alternate nostril pranayamas on cardiovascular parameters and reaction time. Int'l J Yoga 2014; 7: 60-5.

3. Scientific Journal Reviews. Factors Affecting Reaction Time. Available on: https://www. hptinstitute.com/wp-content/uploads/2014/01/ Factors-Affecting-Reaction-Time1.pdf

4. Shah C, Gokhale PA, Mehta HB. Effect of mobile use on reaction time. Al Ameen J Med Sci 2010; 3: 160-4.

5. Ganong WF. Complimentary specialization of the hemispheres versus cerebral dominance. In: Review of Medical Physiology, 25 th edition. New York: McGraw Hill; 2016. p. 290-1.
6. Takeda K,Shimoda N,SatoY,Ogano M,KitoH. Reaction time differences between left and right handers during mental rotation of hand pictures. Laterality. 2010; 15(4). DOI: 10.1080/13576500902938105

7. Kalyanshetti SB, Vastrad BC. Effect of handedness on visual, auditory and cutaneous reaction times in normal subjects. AJMS 2013; 6: 278-80

8. Misra N, Mahajan KK, Maini BK. Comparative study of visual and auditory reaction time of hands and feet in males and females. Ind J Physiol Pharmacol 1985; 29: 213-8.

9. Cournot M, Marquie JC, Ansiau D. Relation between Body Mass Index and Cognitive Function in Healthy Middle Aged Men and Women. Neurology 2006; 67: 1208 - 14. DOI: 10.1212/01.wnl.0000238082.13860.50

10. Gunstad J, Paul RH, Cohaen RA, Tate DF, Gordon E. Obesity is associated with memory deficits in young and middle aged adults. Eat Weight Disord. 2006. 11: 15-9. DOI: $10.1007 /$ BF03327747 
11. Skurvydas A, Gutnik B, Zuoza AK, Nash D, Zuoziene IJ, Mickeviciene D. Relationship between simple reaction time and body mass index. J Compar Human Biol 2009; 60: 77-85.DOI: 10.1016/j.jchb.2008.06.006

12. Nene AS, Pazare PA, Sharma KD. Study of relationship between body mass index and simple reaction time in healthy young females. Indian J Physiol Pharmacol 2011; 55: 228-91.

13. World Health Organization. Body Mass Index - BMI. 2021 Apr 2. Available from: https://www.euro.who. int/en/health-topics/disease-prevention/nutrition/ahealthy-lifestyle/body-mass-index-bmi.

14. Eckner JT, Kutcher JS, Richardson JK. Between seasons test-retest reliability of clinically measured reaction time in national collegiate athletic association division I athletes. J Athl Train 2011; 46: 409-14. DOI: 10.4085/1062-6050-46.4.409

15. Aranha VP, Joshi R, Samule AJ, Sharma K. Catch the moving ruler and estimate reaction time in children. Ind J Med Health Resear 2015; 2: 23-26.

16. Khan ADY, Amalladinna A, Malipatil B. Effect of Body Mass Index and Gender on Visual and Auditory Reaction Times in Young Adults. J US-China Med Sci 2015; 12: 64-9.

17. Deore DN, Surwase SP, Masroor S, Khan ST, Kathore V. A cross sectional study on the relationship between the body mass index and the audiovisual reaction time. J Clin Diag Res 2012; 6: 1466-8.
18. Sudheer C, Jagadeesan S., Kammar KF. Impact of BMI on Visual Reaction Time in Individuals with BMI in Normal Range. Internal J Physiol 201; 5: 10-2.

19. Nikam LH, Gadkari JV. Effect of age, gender, and body mass index on visual and auditory reaction times in Indian population. Ind J Physiol Pharmacol 2012; 56: 94-9.

20. Sabia S, Kivimaki M, Shipley MJ, Marmot MG, Manoux AS. Body mass index over the adult life course and cognition in midlife: the Whitehall II cohort study. Am J Clin Nutr 2009; 89: 601-7.

21. Bruce J, Russell GF. Premenstrual tension: a study of weight changes and balances of sodium, water and potassium. Lancet 1962; 11: 267-271.DOI: 10.1016/ s0140-6736(62)90173-3

22. Jha RK, Thapa S, Kasti R, Nepal O. Influence of Body Mass Index, Handedness and Gender on Ruler Drop Method Reaction Time among Adults. J Nepal Health Res Counc 2020; 18: 108-11. DOI: https://doi. org/10.33314/jnhrc.v18i1.2545

23. Mali BY, Bhatkar RS, Pradhan MP, Kowale AN. Comparison of visual and auditory reaction time of right and left side in right handed young adults. Ind Med Gazet 2012; 316-19.

24. Sathiamoorthy A, Sathiamoorthy SS. Limb dominance and motor conduction velocity of median and ulnar nerves. Ind J Physiol Pharmacol. 1990; 34: 51-3. 